\title{
Design, Synthesis, and Biological Evaluation of Novel Imidazo[1,2-a]pyridine Derivatives as Potent c-Met Inhibitors
}

Chunpu Li, ${ }^{\dagger, \|}$ Jing Ai, ${ }^{\ddagger}, \|$ Dengyou Zhang, ${ }^{\dagger}, \|$ Xia Peng, ${ }^{\ddagger}$ Xi Chen, ${ }^{\dagger}$ Zhiwei Gao, ${ }^{\S}$ Yi Su, ${ }^{\ddagger}$ Wei Zhu, ${ }^{\dagger}$ Yinchun Ji, Xiaoyan Chen, ${ }^{\ddagger}$ Meiyu Geng, ${ }^{*}+\frac{+}{\ddagger}$ and Hong Liu ${ }^{* \dagger}$

${ }^{\dagger}$ CAS Key Laboratory of Receptor Research, and ${ }^{\ddagger}$ Division of Anti-Tumor Pharmacology, Shanghai Institute of Materia Medica, Chinese Academy of Sciences, 555 Zu Chong Zhi Road, Shanghai 201203, P. R. China

${ }^{\S}$ Shanghai Institute of Materia Medica, Chinese Academy of Sciences, 501 Haike Road, Shanghai 201203, P. R. China

Supporting Information

ABSTRACT: A series of imidazo[1,2-a]pyridine derivatives against c-Met was designed by means of bioisosteric replacement. In this study, a selective, potent c-Met inhibitor, 22e was identified, with $\mathrm{IC}_{50}$ values of $3.9 \mathrm{nM}$ against c-Met kinase and $45.0 \mathrm{nM}$ against c-Met-addicted EBC-1 cell proliferation, respectively. Compound 22e inhibited c-Met phosphorylation and downstream signaling across different oncogenic forms in c-Met overactivated cancer cells and model cells. Compound 22e significantly inhibited tumor growth (TGI $=75 \%)$ with good oral bioavailability $(F=29 \%)$ and no

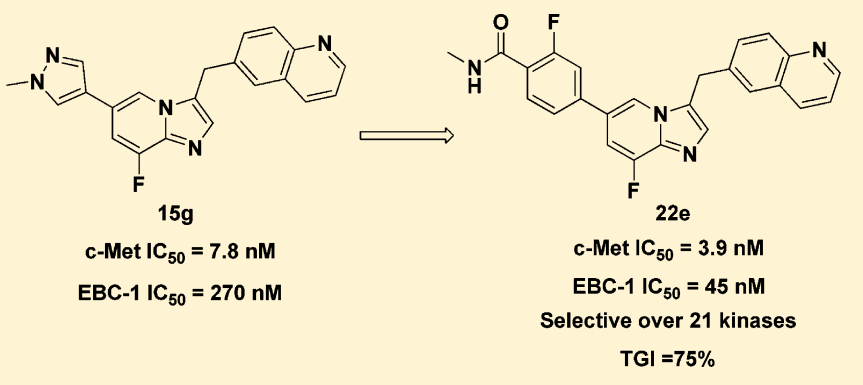
significant hERG inhibition. On the basis of systematic metabolic study, the pathway of all possible metabolites of 22e in liver microsomes of different species has been proposed, and a major NADPH-dependent metabolite 33 was generated by liver microsomes. To block the metabolic site, $\mathbf{4 2}$ was designed and synthesized for further evaluation. Taken together, the imidazo[1,2-a]pyridine scaffold showed promising pharmacological inhibition of c-Met and warrants further investigation.

KEYWORDS: Receptor tyrosine kinase, c-Met inhibitor, imidazo[1,2-a]pyridine, metabolic stability

$\mathrm{R}$ eceptor tyrosine kinases (RTKs) have a critical role in the development and progression of many types of cancer. ${ }^{1}$ The receptor tyrosine kinase c-Met is expressed mainly by epithelial cells of many organs. ${ }^{2}$ Activation of c-Met is regulated upon binding with its natural ligand, hepatocyte growth factor (HGF), ${ }^{3}$ and interaction with other membrane receptors. ${ }^{4}$ The normal functions of $\mathrm{HGF} / \mathrm{c}$-Met pathway are largely restricted to embryogenesis, tissue injury repair, and regeneration in adults. ${ }^{5}$ Dysregulation of the HGF/c-Met pathway (through, e.g., c-Met transcriptional upregulation, MET gene amplification or rearrangement, and activating mutations of $M E T$ gene) can induce cell proliferation, invasion, migration, and apoptosis avoidance, leading to tumor growth, angiogenesis, and metastasis. ${ }^{3}$ Importantly, aberrant c-Met activation observed frequently in many human solid tumors and hematological malignancies is associated with poor clinical outcomes. ${ }^{6}$ Furthermore, overactivation of c-Met causes therapeutic resistance. ${ }^{7}$ For these reasons, c-Met has become an attractive target for cancer therapy.

Recently, a numerous number of small molecule c-Met inhibitors have been reported (Figure 1). Compound 1 $\left(\right.$ Crizotinib) ${ }^{8}$ developed by Pfizer is a potent c-Met/ALK dual inhibitor, which demonstrated marked efficacy for a subset of nonsmall cell lung cancer (NSCLC) patients with an EML4ALK fusion gene. Phase I clinical trial of inhibitor 2 $(\mathrm{JNJ} 38877605)^{9}$ has been terminated because of an increase in serum creatinine levels. Inhibitor 3 (SGX-523) is no longer in clinical development because of acute renal failure. ${ }^{10}$ Without any safety concerns, the clinical study of inhibitor 4 (PF-04217903) ${ }^{11}$ was prematurely discontinued. In addition, compounds 5 (AMG-337) ${ }^{12}$ and 6 (INC-280) ${ }^{13}$ were reported and have entered phase II clinical trials.

Among the known c-Met inhibitors, bicyclic triazole-based or triazine-based inhibitors demonstrated high c-Met inhibitory potency and excellent selectivity against other kinases. However, many projects of these inhibitors in clinical or discovery development were stopped due to toxicity or unknown reasons. ${ }^{9,10,14}$ Thus, there is still a need to discover new classes of inhibitors against c-Met for the treatment of cancer patients. The publicly available cocrystal structure of PF04217903 within c-Met (PDB 3ZXZ) disclosed the binding mode of this kind of inhibitors. ${ }^{11}$ Generally, the quinoline nitrogen atom participates in a hydrogen bond with the hinge region residue Met-1160. The N-3 nitrogen of triazolopyrazine backbone formed a hydrogen bond with Asp-1222. Meanwhile, triazolopyrazine backbone plays an important role in both cMet activity and kinase selectivity via the unique face-to-face $\pi$ stacking interaction with the activation loop residue Tyr-1230, and there is a positive correlation between electron deficiency

Received: November 25, 2014

Accepted: March 1, 2015

Published: March 2, 2015 


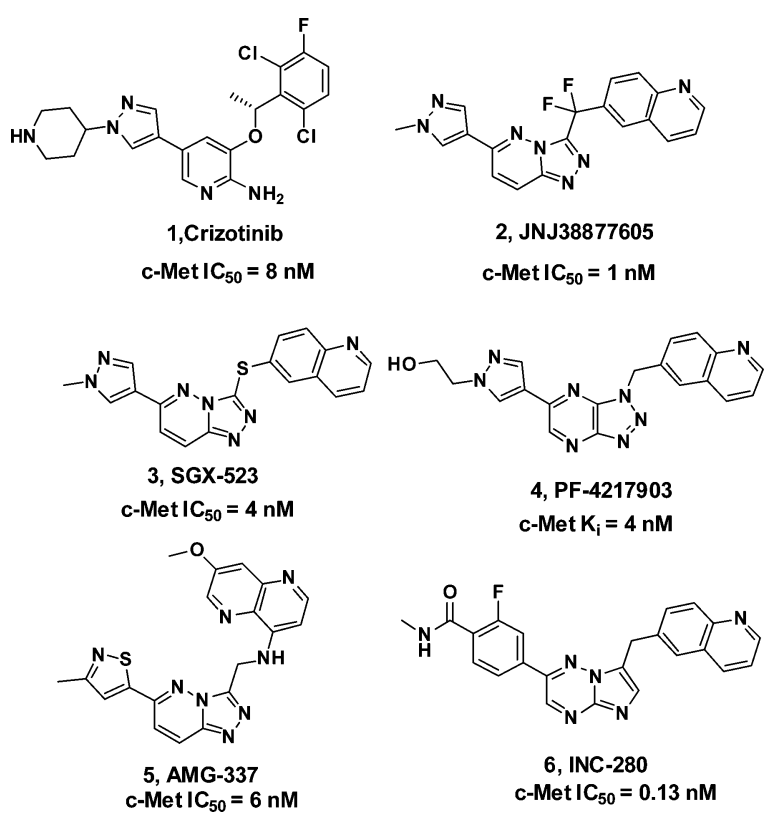

Figure 1. Representative c-Met inhibitors.

of bicyclic aromatic rings and the strength of $\pi-\pi$ interaction with Tyr-1230. ${ }^{11}$ The substituted aryl/heteroaryl (e.g., 1methylpyrazole) on the backbone reaches out into the solvent (Figure 2). Bioisosteric replacement is a powerful method for

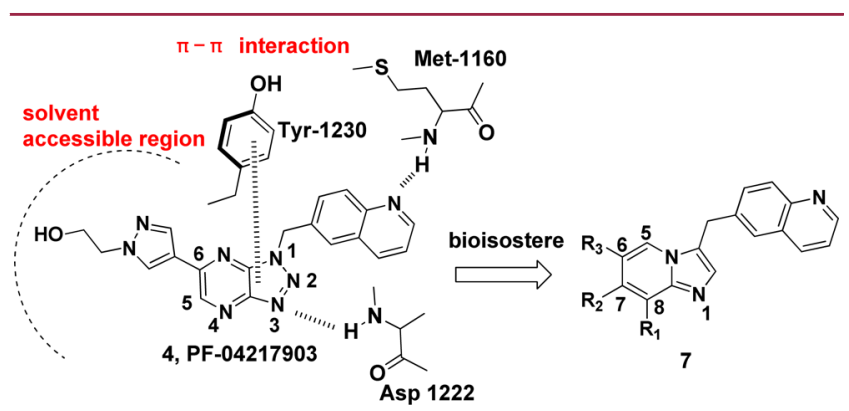

Figure 2. Design of the imidazo[1,2-a]pyridine scaffold.

the identification of novel chemical series in medicinal chemistry. On the basis of the previous work by Merck, 8fluoroimidazo $[1,2-a]$ pyridine has been established as a physicochemical mimic of imidazo[1,2-a]pyrimidine, using both in silico and traditional techniques. ${ }^{15}$ To the best of our knowledge, there are still no examples of using this strategy to discover novel c-Met inhibitors. Hence, we tried to replace the 8-position $\mathrm{N}$ atom with a $\mathrm{C}-\mathrm{F}$ bond to mimic the properties of $\mathrm{N}-8$ atom, including electrostatic surface and lipophilicity to keep the electron deficiency of bicyclic aromatic rings. Meanwhile, we tried to introduce $\mathrm{Cl}, \mathrm{CN}$, and $\mathrm{CF}_{3}$ on the imidazo $[1,2-a]$ pyridine to evaluate the effluence of the electron density of bicyclic aromatic rings on c-Met inhibition. On the basis of the cocrystal structural information and principles of bioisosterism, we designed a novel imidazo[1,2-a]pyridine scaffold as c-Met inhibitors. Herein, we describe our recent effort on the synthesis and SARs of this series of compounds.

To achieve a structure-activity relationship (SAR) exploration, efficient synthetic routes were employed for preparation of the analogues (Schemes 1 and 2 in Supporting Information).

These novel imidazo[1,2-a]pyridine derivatives against c-Met have not been previously synthesized and evaluated; therefore, the initial goal was to identify the optimal substituent. To identify potent c-Met inhibitors efficiently, we initially selected 1-methylpyrazole as a substituent at the C-6 position while varying the $\mathrm{C}-7$ and $\mathrm{C}-8$ substituents (Table 1). The initial

Table 1. SAR of Substituents on the Imidazo $[1,2-a]$ pyridine Scaffold

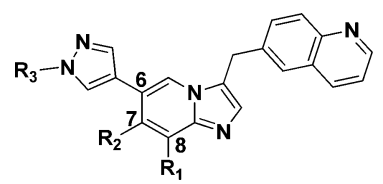

\begin{tabular}{llllcc}
\hline Compd & $\mathrm{R}_{1}$ & $\mathrm{R}_{2}$ & $\mathrm{R}_{3}$ & $\begin{array}{c}\mathrm{IC}_{50} \\
(\mathrm{nM})^{a}\end{array}$ & $\begin{array}{c}\mathrm{EBC}^{b} \\
\mathrm{IC}_{50}(\mu \mathrm{M})\end{array}$ \\
\hline $\mathbf{1 5 a}$ & $\mathrm{Cl}$ & $\mathrm{H}$ & $\mathrm{CH}_{3}$ & $2180 \pm 120$ & $\mathrm{ND}^{c}$ \\
$\mathbf{1 5 b}$ & $\mathrm{H}$ & $\mathrm{Cl}$ & $\mathrm{CH}_{3}$ & $24.5 \% @ 1 \mu \mathrm{M}$ & $\mathrm{ND}$ \\
$\mathbf{1 5 c}$ & $\mathrm{CF}_{3}$ & $\mathrm{H}$ & $\mathrm{CH}_{3}$ & $9.6 \% @ 1 \mu \mathrm{M}$ & $\mathrm{ND}$ \\
$\mathbf{1 5 d}$ & $\mathrm{H}$ & $\mathrm{CF}_{3}$ & $\mathrm{CH}_{3}$ & $5.9 \% @ 1 \mu \mathrm{M}$ & $\mathrm{ND}$ \\
$\mathbf{1 5 e}$ & $\mathrm{CN}$ & $\mathrm{H}$ & $\mathrm{CH}_{3}$ & $34.5 \% @ 100 \mu \mathrm{M}$ & $\mathrm{ND}$ \\
$\mathbf{1 5 f}$ & $\mathrm{H}$ & $\mathrm{CN}$ & $\mathrm{CH}_{3}$ & $33.3 \% @ 100 \mu \mathrm{M}$ & $\mathrm{ND}$ \\
$\mathbf{1 5 g}$ & $\mathrm{F}$ & $\mathrm{H}$ & $\mathrm{CH}_{3}$ & $7.8 \pm 0.3$ & $0.27 \pm 0.05$ \\
$\mathbf{1 5 h}$ & $\mathrm{F}$ & $\mathrm{H}$ & $\mathrm{HO}_{*}$ & $3.2 \pm 0.3$ & $0.34 \pm 0.03$ \\
$\mathbf{1 5 i}$ & $\mathrm{F}$ & $\mathrm{H}$ & $\mathrm{HN}^{*}$ & $11.1 \pm 1.7$ & $1.46 \pm 0.02$ \\
\hline
\end{tabular}

${ }^{a} \mathrm{IC}_{50}$ values were calculated by the Logit method from the results of at least two independent tests with eight concentrations each and expressed as mean $\pm \mathrm{SD}$; c-Met $\mathrm{IC}_{50}$ of Crizotinib $=2.4 \pm 0.1 \mathrm{nM}$; cMet $\mathrm{IC}_{50}$ of JNJ38877605 $=1.8 \pm 0.3 \mathrm{nM}$. ${ }^{b} \mathrm{EBC}-1$ : human nonsmallcell lung cancer cell line that expresses elevated levels of constitutively active c-Met. ${ }^{c}$ Not detected.

biochemical assay found that compound 15a exhibited moderate activity with an enzymatic $\mathrm{IC}_{50}$ of $2.18 \mu \mathrm{M}$ against c-Met. The activity did not significantly change with the introduction of different substituents at the C-7 or C-8 position $(\mathbf{1 5 b}-\mathbf{1 5 f})$. To our delight, compound $15 \mathrm{~g}$ exhibited c-Met inhibition with an enzymatic $\mathrm{IC}_{50}$ of $7.8 \mathrm{nM}$ and an EBC-1 cell $\mathrm{IC}_{50}$ of $0.27 \mu \mathrm{M}$, respectively. These encouraging results prompted us to investigate the SAR for substituents on the pyrazole while keeping the fluorine substitute at the C-8 position. The incorporation of polar groups, such as an ethanolic group (15h) and a piperidine group (15i) on the pyrazole of $15 \mathrm{~g}$ resulted in 1.2-fold and 5.4-fold loss of cellular potency, respectively.

To gain structural information for further optimization, the 3D proposed binding modes of representative compounds 15a, $15 \mathrm{c}, 15 \mathrm{e}$, and $15 \mathrm{~g}$ were generated by docking simulation (Figure 3). For each compound, the best pose with the lowest binding energy was selected for further analysis with Glide ${ }^{16}$ and PyMOL. ${ }^{17}$ The binding mode indicated that compound $15 \mathrm{~g}$ was bound to the active site of c-Met, similar to PF04217903 (Figure 3A). The nitrogen of quinoline H-bonds well with the hinge region Met-1160, whereas the N-1 nitrogen of the imidazo[1,2-a]pyridine scaffold formed a hydrogen bond with Asp-1222. In addition, imidazo[1,2-a]pyridine core kept a $\pi-\pi$ interaction with electron rich Tyr-1230, which is critical for c-Met inhibition. Compared with $\mathbf{1 5 g}$, the binding pose of 15c (Figure 3B) was entirely different since the bulky C-8 $\mathrm{CF}_{3}$ substituent could not enter the inside pocket, which could be the main reason for the loss in inhibitory activity. Compared 


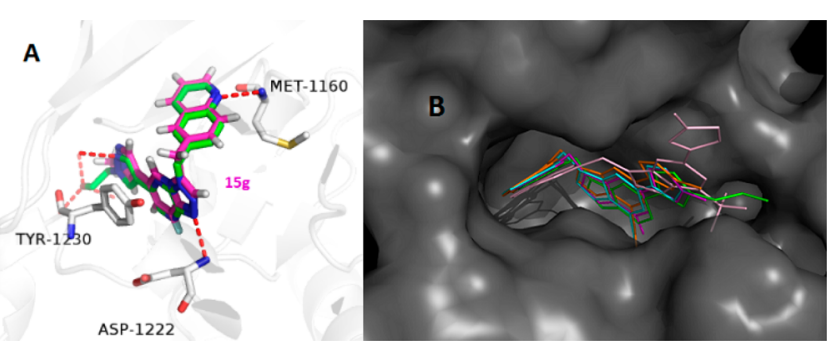

Figure 3. Binding model comparison of designed compounds with PF04217903. (A) Binding pose of compound 15g (purple) and PF04217903 (green) with c-Met. (B) Overlay of 15a (blue), 15c (pink), 15e (orange), and 15g (purple) in the same cavity along with PF04217903 (green) as the reference molecule.

with 8-fluoroimidazo[1,2-a]pyridine core $(\mathbf{1 5 g})$, the 8chloroimidazo $[1,2-a]$ pyridine is more electron-rich, leading to a decreased interaction with Tyr-1230. Taken together, these results could give an explanation to the different inhibition of these compounds.

Subsequently, the SAR at the 6-position of the imidazo[1,2a]pyridine scaffold was investigated (Table 2). Introduction of heteroaryl substituents $(16 a-c)$ displayed good c-Met inhibition. The pyridinyl analogue $16 \mathrm{~b}$, which incorporated a cyano group, was more effective, and the EBC-1 cell $\mathrm{IC}_{50}$ reached to $188.5 \mathrm{nM}$. Among the phenyl derivatives $(\mathbf{1 6 d}-\mathrm{g})$, benzonitrile analogues $\mathbf{1 6} \mathbf{d}$ and $\mathbf{1 6 f}$ demonstrated improved cMet inhibition, with an EBC-1 cell $\mathrm{IC}_{50}$ of 106.7 and $145.0 \mathrm{nM}$, respectively. These observations indicated that incorporation of polar groups on 6-phenyl had a significant influence on cellular activity. Encouraged by these results, analogues incorporated by polar amide groups on 6-phenyl were prepared for SAR exploration. 6-Benzamide analogue 22a displayed 4-fold loss in cellular activity compared with 16d. Derivatives bearing 4fluoro-3- $N$-methylbenzamide (22b) and 4-chloro-3- $N$-methylbenzamide (22c) groups displayed less potent c-Met inhibition than 22a. However, derivatives bearing 3-methoxy-4-Nmethylbenzamide (22d) and 3-fluoro-4- $\mathrm{N}$-methylbenzamide (22e) groups exhibited remarkably improved cellular activity. In particular, compound 22e showed an enzymatic $\mathrm{IC}_{50}$ of 3.9 $\mathrm{nM}$ and good EBC-1 cell $\mathrm{IC}_{50}$ of $45.0 \mathrm{nM}$. These results indicated that the $3-\mathrm{F}$ and $3-\mathrm{OMe}$ might be important for $\mathrm{c}$ Met inhibition.

To further modulate physical chemical properties of these inhibitors, substituted amides were introduced, especially amides with polar groups such as basic amines on their $N$ terminus (Table 3 ). First, the $N, N^{\prime}$-disubstituted amide analogues were evaluated. Compounds $22 \mathrm{f}$ and $22 \mathrm{~g}$ showed an EBC-1 cell $\mathrm{IC}_{50}$ of 405.5 and $868.9 \mathrm{nM}$, respectively, suggesting that $\mathrm{N}$-monosubstituents were preferred here. Next, we investigated the influence of monosubstitution of the $\mathrm{N}$ terminus of the amide on c-Met inhibition. For example, compound $22 \mathrm{~h}$, which contained a morpholinoethyl group on the $\mathrm{N}$-terminus of the amide, demonstrated c-Met inhibition by 2-fold compared with 22e, and there was no significant differences between their EBC-1 activity. Replacement of the morpholinoethyl group with a noncyclic dimethylaminoethyl group (compound 22i, enzymatic $\mathrm{IC}_{50}=2.4 \mathrm{nM}$ and EBC-1 cell $\mathrm{IC}_{50}=49 \mathrm{nM}$ ) slightly improved the cell inhibitory activity. Compound $22 \mathrm{j}$, with a longer C-chain of the amide, reduced EBC-1 cell inhibitory activity by 3 -fold. We also investigated the SARs of the compounds by restricting the side-chain conformation at the $\mathrm{N}$-terminus of the amides (compounds
Table 2. SAR at the 6-Position of the Imidazo $[1,2-a]$ pyridine Scaffold

22a

${ }^{a} \mathrm{IC}_{50}$ values were calculated by the Logit method from the results of at least two independent tests with eight concentrations each and expressed as mean $\pm \mathrm{SD}$; c-Met $\mathrm{IC}_{50}$ of Crizotinib $=2.4 \pm 0.1 \mathrm{nM}$; cMet $\mathrm{IC}_{50}$ of JNJ38877605 $=1.8 \pm 0.3 \mathrm{nM} .{ }^{b} \mathrm{EBC}-1$ : human nonsmallcell lung cancer cell line that expresses elevated levels of constitutively active c-Met.

22k, 22l, and 22o). When the $N$-terminus of the amide was replaced with a piperidin-2-ylmethyl group (compound 22k, EBC cell $\mathrm{IC}_{50}=276.8 \mathrm{nM}$ ) or a piperidin-3-yl group (compound 221, EBC cell $\mathrm{IC}_{50}=137.5 \mathrm{nM}$ ), c-Met inhibition was 5.5- and 4.3-fold more potent than $22 \mathrm{e}$, respectively. In addition, we investigated compounds that contained an aryl group or a heteroaryl group on the $N$-terminal side of the amides. Compound $\mathbf{2 2} \mathrm{m}$ showed sharply decreased c-Met cell inhibition, which could be caused by an intramolecular hydrogen bond interaction between the hydrogen atom of 
Table 3. SAR of Substituents on the Amides

(22)

${ }^{a} \mathrm{IC}_{50}$ values were calculated by the Logit method from the results of at least two independent tests with eight concentrations each and expressed as mean $\pm \mathrm{SD}$; c-Met $\mathrm{IC}_{50}$ of Crizotinib $=2.4 \pm 0.1 \mathrm{nM}$; cMet $\mathrm{IC}_{50}$ of JNJ38877605 $=1.8 \pm 0.3 \mathrm{nM} .{ }^{b} \mathrm{EBC}-1$ : human nonsmallcell lung cancer cell line that expresses elevated levels of constitutively active c-Met.

the amide and the pyridine nitrogen. The potency of compound 22n against EBC-1 cell proliferation is comparable to that of optimal compound 22e.
Given its promising enzymatic and cellular potency, 22e was selected as the lead compound for subsequent evaluation. In contrast to its high potency against c-Met, 22e had barely any inhibitory effect on the other 21 tested kinases, including c-Met family member RON and highly homologous kinases Axl, cMer, and Tyro-3 $\left(\mathrm{IC}_{50}>10 \mu \mathrm{M}\right)$, indicating that 22e was a selective c-Met inhibitor (Table S1 in Supporting Information).

As shown in Figure S1 (See Supporting Information), 22e inhibited the phosphorylation of c-Met and its key downstream molecules Akt and Erk in a dose-dependent manner in representative cancer or model cell lines (EBC-1, MKN45, and BaF3/TPR-Met cells). These results suggested that 22e suppressed c-Met signaling across different oncogenic forms in c-Met overactivated cells.

Compound 22e significantly inhibited cell proliferation of EBC-1, MKN-45, SNU-5, and BaF3/TPR-Met cells, which are characterized by a c-Met-dependent cell growth, with an $\mathrm{IC}_{50}$ value of 45.0 to $203.2 \mathrm{nM}$ (Table 4); however, 22e barely

Table 4. Effects of 22e on Cell Proliferation

\begin{tabular}{lccc}
\multicolumn{1}{c}{$\mathrm{IC}_{50}(\mathrm{nM})^{a}$} & $\mathbf{2 2 e}$ & $\mathrm{JNJ}^{a} 38877605$ & Crizotinib \\
EBC-1 & $45.0 \pm 12.7$ & $9.5 \pm 2.0$ & $21.8 \pm 6.5$ \\
MKN-45 & $90.9 \pm 17.4$ & $10.9 \pm 0.4$ & $38.1 \pm 8.8$ \\
SNU-5 & $70.2 \pm 19.6$ & $15.8 \pm 3.2$ & $20.4 \pm 14.4$ \\
BaF3/TPR-Met & $203.2 \pm 4.4$ & $17.6 \pm 2.2$ & $127.4 \pm 8.1$
\end{tabular}

${ }^{a_{T}}$ The $\mathrm{IC}_{50}$ values are shown as the mean $\pm \mathrm{SD}(\mathrm{nM})$ from three separate experiments.

inhibited these other cell lines, of which had Met low expression or activation $\left(\mathrm{IC}_{50}>50 \mu \mathrm{M}\right.$ ) (Figure $\mathrm{S} 2 \mathrm{~A}$ in Supporting Information). c-Met inhibition blocks cell proliferation via arresting cells in G1/S phase. ${ }^{18}$ Compound 22e induced a G1/S phase arrest in the EBC-1 cells, with $81.84 \%$ of the cell population in $\mathrm{G} 1$ phase in the presence of $1 \mu \mathrm{M} 22 \mathrm{e}$ (versus $52.95 \%$ in the vehicle control group) (Figure S2B,C in Supporting Information).

The HGF/c-Met axis activation promotes cell invasion and migration to allow cancer metastasis. ${ }^{19}$ Compound 22e inhibited the migration of HGF-induced NCI-H441 cells, and almost completely blocked the cell migration phenotype at a dose of $500 \mathrm{nM}$ (Figures S3A,C in Supporting Information). Further, 22e strongly suppressed the invasion of HGF-induced NCI-H441 cell (Figures S3B,D in Supporting Information).

Cell scattering induced by $\mathrm{HGF} / \mathrm{c}-\mathrm{Met}$ activation is a hallmark of cancer invasiveness and metastasis. ${ }^{20}$ Upon HGF stimulation, epithelial cells undergo colony dispersal and become migratory, fibroblast-like cells. ${ }^{21}$ Compound $22 \mathrm{e}$ treatment reduced HGF-induced cell scattering of MDCK canine kidney epithelial cells in a dose-dependent manner (Figures S4 in Supporting Information). Collectively, these results indicated that $22 \mathrm{e}$ inhibited the metastasis and invasiveness phenotype evoked by the HGF/c-Met axis in cancer.

Upon HGF stimulation, c-Met induces several biological responses that collectively give rise to a program known as invasive growth, which is pivotal to drive cancer cell invasion and metastasis. ${ }^{22}$ Thus, we investigated whether 22e inhibited c-Met-mediated invasive growth. Exposure to 22e inhibited branching morphogenesis in MDCK cells (Figures S5 in Supporting Information), indicating the 22e inhibited HGFinduced c-MET-mediated invasive growth. 
The pharmacokinetic (PK) profiles of the selected compound 22e were assessed in Sprague-Dawley (SD) rats (Table S2 in Supporting Information). Compound 22e showed a high area under the curve $\left(\mathrm{AUC}_{0-\infty}\right)$ when dosed orally. The half-life and the absolute oral bioavailability of compound $22 \mathrm{e}$ were $1.17 \mathrm{~h}$ and $29.4 \%$, respectively.

We used the ultraperformance liquid chromatography quadrupole time-of-flight mass spectrometry (UPLC-qTOFMS) method to identify the possible metabolites of 22e in liver microsomes of different species. We have proposed the metabolism pathway and all the metabolites of 22e (Scheme $3 a$ in Supporting Information). In view of the result that the major oxidant metabolism take place in the benzyl position of this scaffold, we speculated that metabolite 33 was the major metabolite of $22 \mathrm{e}$ after incubation in mice, dog, monkey, and human liver microsomes, except rat liver microsomes (Table S3 in Supporting Information).

The $\mathrm{IC}_{50}$ value of compound 22e on hERG was $93.56 \mu \mathrm{M}$ using a FluxOR thallium assay. Thus, 22e did not show significant hERG inhibition.

To assess the in vivo antitumor efficacy of 22e, an EBC-1 xenograft model specifically driven by $M E T$ amplification was chosen. After 21 days of $22 \mathrm{e}$ (methanesulfonic salt) oral administration, dose-dependent tumor growth inhibition was observed in 22e treated groups, with an inhibitory rate of $75.0 \%$ $(P<0.05)$ and $62.9 \%(P<0.05)$ at doses of 100 and $50 \mathrm{mg} / \mathrm{kg}$, respectively (Figure 4). No significant weight losses were observed (data not shown).

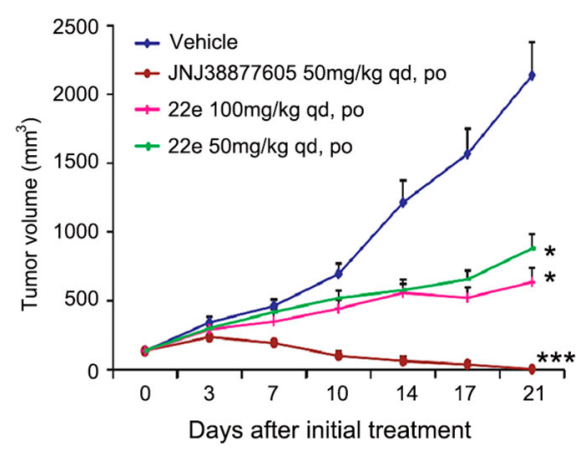

Figure 4. Compound 22e inhibits tumor growth in EBC-1 xenografts. Compound 22e in the methanesulfonic acid salt form or JNJ38877605 was administered orally once daily for 3 weeks after the tumor volume reached 100 to $150 \mathrm{~mm}^{3}$. The results are expressed as the mean \pm SEM (drug-treated group, $n=6$; vehicle group, $n=12$ ). ${ }^{*} p<0.05$, $* * * p<0.001$ vs control group, determined using Student's $t$ test.

Furthermore, we synthesized the major metabolite 33 for investigation (Scheme $3 \mathrm{~b}$ in Supporting Information); however, it had no significant inhibitory effect on c-Met-dependent cell proliferation (enzymatic $\mathrm{IC}_{50}=82.9 \pm 25.9 \mathrm{nM}$ and $\mathrm{EBC}-1$ cell $\left.\mathrm{IC}_{50}=3022.3 \mathrm{nM}\right)$. Since we have identified metabolic hot spots of 22e, we designed and synthesized compound $\mathbf{4 2}$ (Scheme 4 in Supporting Information), which bears a cyclopropyl at the linker of this scaffold that might block the metabolic site. ${ }^{23}$ Even though $\mathbf{4 2}$ demonstrated potent inhibitory effect on c-Met kinase and c-Met-dependent cell viability (enzymatic $\mathrm{IC}_{50}=23.5 \mathrm{nM}$ and $\mathrm{EBC}-1$ cell $\mathrm{IC}_{50}=60.0$ $\mathrm{nM}$ ), the in vivo antitumor efficacy of $\mathbf{4 2}$ was disappointing. Further optimization to improve the metabolic stability and in vivo antitumor efficacy are ongoing in our laboratory.
In conclusion, a series of novel imidazo $[1,2-a]$ pyridine derivatives were designed, synthesized, and evaluated as cMet inhibitors by means of bioisosteric replacement. SAR exploration led to the identification of a potent, selective c-Met inhibitor 22e. Compound 22e showed strong potency against c-Met kinase and inhibited c-Met phosphorylation and downstream signaling across different oncogenic forms in cMet overactivated cancer cells and model cells. Furthermore, 22e treatment resulted in significant antitumor activity in cMet-driven EBC-1 xenografts. Compound $\mathbf{4 2}$ was designed by means of metabolite identification. Further optimizations are currently under investigation.

\section{ASSOCIATED CONTENT}

\section{S Supporting Information}

Synthetic procedures and analytical data for compounds reported in this letter and procedures for in vitro and in vivo assays. This material is available free of charge via the Internet at http://pubs.acs.org.

\section{AUTHOR INFORMATION}

\section{Corresponding Authors}

*(M.G.) E-mail: mygeng@simm.ac.cn. Phone: +86-2150806600-2426.

*(H.L.) E-mail: hliu@simm.ac.cn. Phone: +86-21-50807042.

\section{Author Contributions}

${ }^{\|}$C.L., J.A., and D.Z. contributed equally to this work.

\section{Funding}

We gratefully acknowledge financial support from the National Natural Science Foundation of China (Grants 91229204 and 81220108025), Major Project of Chinese National Programs for Fundamental Research and Development (2015CB910304), National High Technology Research and Development Program of China (2012AA020302), National Basic Research Program of China (2012CB518005), and National ST Major Projects (2012ZX09103101-072, 2014ZX09507002-001, and 2013ZX09507-001).

\section{Notes}

The authors declare no competing financial interest.

\section{ABBREVIATIONS}

c-Met, mesenchymal-epithelial transition factor; ALK, anaplastic lymphoma kinase; SARs, structure-activity relationships; AUC, area under curve

\section{REFERENCES}

(1) Zwick, E.; Bange, J.; Ullrich, A. Receptor tyrosine kinase signalling as a target for cancer intervention strategies. Endocr. Relat. Cancer 2001, 8, 161-173.

(2) Trusolino, L.; Comoglio, P. M. Scatter-factor and semaphorin receptors: cell signalling for invasive growth. Nat. Rev. Cancer 2002, 2, 289-300.

(3) Bottaro, D. P.; Rubin, J. S.; Faletto, D. L.; Chan, A. M.; Kmiecik, T. E.; Vande Woude, G. F.; Aaronson, S. A. Identification of the hepatocyte growth factor receptor as the c-met proto-oncogene product. Science 1991, 251, 802-804.

(4) Garouniatis, A.; Zizi-Sermpetzoglou, A.; Rizos, S.; Kostakis, A.; Nikiteas, N.; Papavassiliou, A. G. Vascular endothelial growth factor receptors 1,3 and caveolin-1 are implicated in colorectal cancer aggressiveness and prognosis-correlations with epidermal growth factor receptor, CD44v6, focal adhesion kinase, and c-Met. Tumour Biol. 2013, 34, 2109-2117. 
(5) Porter, J. Small molecule c-Met kinase inhibitors: a review of recent patents. Expert Opin. Ther. Pat. 2010, 20, 159-177.

(6) Parr, C.; Watkins, G.; Mansel, R. E.; Jiang, W. G. The hepatocyte growth factor regulatory factors in human breast cancer. Clin. Cancer Res. 2004, 10, 202-211.

(7) Engelman, J. A.; Zejnullahu, K.; Mitsudomi, T.; Song, Y.; Hyland, C.; Park, J. O.; Lindeman, N.; Gale, C. M.; Zhao, X.; Christensen, J.; Kosaka, T.; Holmes, A. J.; Rogers, A. M.; Cappuzzo, F.; Mok, T.; Lee, C.; Johnson, B. E.; Cantley, L. C.; Janne, P. A. MET amplification leads to gefitinib resistance in lung cancer by activating ERBB3 signaling. Science 2007, 316, 1039-1043.

(8) Cui, J. J.; Tran-Dube, M.; Shen, H.; Nambu, M.; Kung, P. P.; Pairish, M.; Jia, L.; Meng, J.; Funk, L.; Botrous, I.; McTigue, M.; Grodsky, N.; Ryan, K.; Padrique, E.; Alton, G.; Timofeevski, S.; Yamazaki, S.; Li, Q.; Zou, H.; Christensen, J.; Mroczkowski, B.; Bender, S.; Kania, R. S.; Edwards, M. P. Structure based drug design of crizotinib (PF-02341066), a potent and selective dual inhibitor of mesenchymal-epithelial transition factor (c-MET) kinase and anaplastic lymphoma kinase (ALK). J. Med. Chem. 2011, 54, 6342-6363.

(9) Clinical trial data: https://www.clinicaltrials.gov/ct2/show/ NCT00651365.

(10) Diamond, S.; Boer, J.; Maduskuie, T. P., Jr.; Falahatpisheh, N.; Li, Y.; Yeleswaram, S. Species-specific metabolism of SGX523 by aldehyde oxidase and the toxicological implications. Drug Metab. Dispos. 2010, 38, 1277-1285.

(11) Cui, J. J.; McTigue, M.; Nambu, M.; Tran-Dube, M.; Pairish, M.; Shen, H.; Jia, L.; Cheng, H.; Hoffman, J.; Le, P.; Jalaie, M.; Goetz, G. H.; Ryan, K.; Grodsky, N.; Deng, Y. L.; Parker, M.; Timofeevski, S.; Murray, B. W.; Yamazaki, S.; Aguirre, S.; Li, Q.; Zou, H.; Christensen, J. Discovery of a novel class of exquisitely selective mesenchymalepithelial transition factor (c-MET) protein kinase inhibitors and identification of the clinical candidate 2-(4-(1-(quinolin-6-ylmethyl)$1 \mathrm{H}-[1,2,3]$ triazolo[4,5-b]pyrazin-6-yl)-1H-pyrazol-1 -yl)ethanol (PF04217903) for the treatment of cancer. J. Med. Chem. 2012, 55, 80918109.

(12) Clinical trial data: https://www.clinicaltrials.gov/ct2/show/ NCT02016534.

(13) Clinical trial data: https://www.clinicaltrials.gov/ct2/show/ NCT01737827.

(14) Clinical trial data: https://www.clinicaltrials.gov/ct2/show/ NCT00706355.

(15) Humphries, A. C.; Gancia, E.; Gilligan, M. T.; Goodacre, S.; Hallett, D.; Merchant, K. J.; Thomas, S. R. 8-Fluoroimidazo[1,2a]pyridine: synthesis, physicochemical properties and evaluation as a bioisosteric replacement for imidazo $[1,2-a]$ pyrimidine in an allosteric modulator ligand of the GABA A receptor. Bioorg. Med. Chem. Lett. 2006, 16, 1518-1522.

(16) Glide, version 5.5, Schrödinger, LLC, New York, NY, 2009.

(17) PyMOL, Version 1.4.1, Schrödinger, LLC, New York, NY, 2011.

(18) Bertotti, A.; Burbridge, M. F.; Gastaldi, S.; Galimi, F.; Torti, D.; Medico, E.; Giordano, S.; Corso, S.; Rolland-Valognes, G.; Lockhart, B. P.; Hickman, J. A.; Comoglio, P. M.; Trusolino, L. Only a subset of Met-activated pathways are required to sustain oncogene addiction. Sci. Signaling 2009, 2, ra80.

(19) Jeffers, M.; Rong, S.; Vande Woude, G. F. Hepatocyte growth factor/scatter factor-Met signaling in tumorigenicity and invasion/ metastasis. J. Mol. Med. 1996, 74, 505-513.

(20) Stoker, M.; Gherardi, E.; Perryman, M.; Gray, J. Scatter factor is a fibroblast-derived modulator of epithelial cell mobility. Nature 1987, 327, 239-242.

(21) Thiery, J. P. Epithelial-mesenchymal transitions in tumour progression. Nat. Rev. Cancer 2002, 2, 442-54.

(22) Gherardi, E.; Birchmeier, W.; Birchmeier, C.; Vande Woude, G.; Targeting, M. E. T. in cancer: rationale and progress. Nat. Rev. Cancer 2012, 12, 89-103.

(23) Zhou, J.; Metcalf, B.; Xu, M.; He, C.; Zhang, C.; Qian, D.; Burns, D. M.; Li, Y.; Yao, W. Imidazotriazines and Imidazopyrimidines as kinase inhibitors. PCT Int. Appl. WO 2008/064157A1, 2008. 